\title{
TODAS AS MANHÃS DO MUNDO
}

\author{
Ruth Silviano Brandão
}

UFMG

\begin{abstract}
RESU MO
Este texto reflete sobre o livro Todas as manhãs do mundo, de Pascal Quignard e o filme homônimo, que trata da relação do músico Senhor de Sainte-Colombe e seu discípulo Marin Marais. Essa relação coloca a questão do que é a música e a possibilidade de seu ensino.
\end{abstract}

\section{PALAVRAS - CHAVE}

romance, filme, musicalidade, imagens visuais

Tous les matins du monde sont sans retour.

Todas as manhãs do mundo, ${ }^{1}$ um filme visto, ouvido e gravado na memória, pela beleza dos diálogos, das músicas de Sainte-Colombe, de Marin Marais, de Lully, das imagens cuidadosamente construídas, como telas-réplicas do pintor Georges de La Tour. Nem sempre se liga o nome do filme ao livro que o inspira ou ao autor que o escreveu. No filme a que me refiro, o nome do escritor é Pascal Quignard, autor de Tous les matins $d u$ monde. ${ }^{2}$

Pouco conhecido no Brasil, esse escritor fascinante, por seus textos, sua erudição e seu amor à música, escreveu Tous les matins du monde, sobre um músico e sua enorme melancolia por uma perda sem remédio e sem esquecimento: a morte de sua amada, sua mulher, mãe de suas filhas. Assim começa o livro e essa é uma das primeiras imagens do filme, nascidas do relato de Marin Marais, discípulo de Sainte-Colombe. Desse homem, fala o narrador de Tous les matins $d u$ monde, o romance:

Na primavera de 1650, Madame de Sainte Colombe morreu. Ela deixou duas filhas de dois e seis anos. Monsieur de Sainte Colombe nunca se consolou da morte de sua esposa. Ele a amava. Foi nesta ocasião que ele escreveu "O túmulo das lamúrias". (TLMM, p.9)

Em Pascal Quignard, a música é marca, destino de sua escrita, lugar de contínua ruminação sobre os mesmos temas: a solidão, o silêncio, a perda de um som, de uma palavra, de algo nunca mais reencontrado. Talvez seja possível afirmar

${ }^{1}$ O filme Todas as manhãs do mundo, baseado na obra homônima de Pascal Quignard, foi dirigido por Alain Corneau e tem com intérpretes principais Gerard Depardieu, Jean-Pierre Marielle, Anne Brochet, Guillaume Depardieu e Carole Richert. Pascal Quignard trabalhou na adaptação dos diálogos e no roteiro do filme que ganhou 8 prêmios do César 91, a maior premiação do cinema francês.

${ }^{2}$ Quignard. Tous les matins du monde. (O livro será citado com as iniciais TLMM. As citações no corpo do presente texto foram traduzidas por mim.) 
que, antes da música, haja o silêncio e esse silêncio seja a ausência de uma voz, de uma determinada voz.

Monsieur de Sainte-Colombe, mudo de dor pela presença de uma ferida mortal na alma, tornou-se cada vez mais taciturno, fechou-se em casa e consagrou-se totalmente à música, diz o romance, exibe o filme.

A descrição desse homem estende-se por várias páginas do romance, construindose para o leitor a imagem de uma personagem, cujo traço mais forte era o silêncio o silêncio na música; o silêncio, condição da música. Silêncio e música, na figura de Sainte-Colombe; solidão, silêncio e música, na obra toda de Pascal Quignard, talvez mesmo na sua vida, e talvez por isso Chantal Lapeyre-Desmaison intitula um de seus livros sobre o autor: Pascal Quignard le solitaire. ${ }^{3}$ Impossível separar sua obra de sua vida e, lendo sobre uma, a leitura da outra se torna mais rica, mais clara, para o leitor e o espectador do filme.

Literatura e cinema são diferentes sistemas semióticos e inútil seria cobrar do segundo fidelidade em relação ao primeiro. Entretanto, é uma tarefa tentadora ir atrás das semelhanças e diferenças entre as duas produções e ver como a releitura que é o filme se produz. Neste caso especial, podemos afirmar que o escritor aí se relê, na adaptação que faz de seu texto para o cinema e no trabalho do roteiro.

A descrição literária de Sainte-Colombe concretiza-se de forma surpreendente no ator Jean-Pierre Marielle, que o interpreta no filme: a postura, a voz, o olhar dramatizam a solidão quase selvagem, envolvida pelo enorme silêncio que a abriga, a contenção afetiva, a falta de palavras:

O caráter do Senhor de Sainte-Colombe e sua pouca disposição para a linguagem estavam de acordo com seu extremo pudor e seu rosto permanecia inexpressivo e severo diante de qualquer sentimento. Apenas em suas composições seria possível descobrir a complexidade e a delicadeza do mundo escondido sob essa fisionomia e por detrás dos gestos raros e rígidos. (TLMM, p.22)

Imagem e música, o filme Todas as manhãs do mundo enlaça visibilidade e musicalidade, numa medida diversa do livro, em que falta essa dimensão, pela natureza mesmo da palavra impressa. No livro, entretanto, a música ecoa para o leitor e sua ausência material tematiza, de certa forma, a voz perdida, a busca de um som para sempre inaudível, mas cuja audição se torna possível em toda sua dramaticidade, no filme.

Uma narrativa sobre a música, uma narrativa sobre uma família de três pessoas, um conjunto de três violas: ${ }^{4}$ um pai e suas filhas, um trio afinado que faz música, sob a mestria do mestre-músico e sua dor. Percebe-se nesse conjunto de personagens e seus instrumentos uma lógica semiótica, em que a viola é um instrumento musical carregado de grande carga simbólica e densidade emocional, na medida em que tem a ver com a memória da mulher amada e do erotismo vivido com ela por esse marido silencioso, mesmo na alegria.

E a viola circula no texto, como circula entre as várias mãos, tocado de forma diversa pelos vários dedos, abraçado pelo músico como se abraça, mantendo entre

\footnotetext{
${ }^{3}$ Lapeyre-Desmaison. Pascal Quignard le solitaire.

${ }^{4}$ Trata-se de um tipo de viola: a viola de gamba, antiga família de instrumentos, semelhantes ao violino, com 5 ou 6 cordas, que se tocava prendendo-se verticalmente entre os joelhos.
} 
as pernas, o corpo de uma mulher e o amor a ele perdidos na morte: perda e música de uma paixão que só fala através de suas formas e de seu tato. Não que o silêncio seja uma anterioridade necessária à música, mas é sua sombra, é seu suplemento, podemos, talvez, dizer.

E esse trio que é uma família e uma orquestra ou, mais adequadamente, um conjunto matemático, musical é acrescido de um quarto elemento que o descompleta, que o desestabiliza: o jovem músico Marin Marais. Esse jovem Marin Marais, que vem buscar a mestria de Sainte-Colombe, é também ferido, como os membros dessa família, pela perda de uma voz, sua voz infantil, feminina, de cantor do coro de Saint-Germainl' Auxerrois.

Em outro de seus livros, ${ }^{5}$ Pascal Quignard fala da mudança de voz, que é acesso à sexualidade e perda, no homem, da feminilidade da mãe, da voz materna que o habita visceralmente, na primeira fusão que se dá na carne. Essa nostalgia, que faz sofrer Marin Marais, é motivo persistente na obra de Pascal Quignard e pode sem dúvida ser lido como repetição da experiência de castração, angústia de castração. Perder a voz da infância equivale a uma ferida na garganta, ferida que tira a voz e tira a palavra. E, então, diz o narrador de Tous les matins du monde, Marin Marais prometeu a si mesmo que "ele se vingaria da voz que o havia abandonado, que ele se tornaria um violista renomado". (TLMM, p.44)

Entretanto, Sainte-Colombe não acredita que Marais possa ser um músico, pois para ele uma coisa é ser um músico, outra é tocar música. E ser um músico tem a ver com a radicalidade da solidão, da não submissão ao outro, seja ele o rei ou toda sua corte.

A conquista de uma insociabilidade, de uma liberdade que nada será capaz de invadir ou perturbar são condições da construção de um sujeito e seu desejo. Isso se presentifica na obra de Quignard e em sua vida, configurando-se, não como uma idiossincrasia digna de curiosidade, mas da dignidade mesmo do trabalho criador: "je n' appartiens qu' à moi-même”, grita Sainte-Colombe ao representante do rei, que lhe oferece a fama e a riqueza da corte.

Em Sainte-Colombe e Pascal Quignard exibe-se a mesma necessidade crucial de solidão e de liberdade, a mesma renúncia ao mundo e seus apelos. Então no lugar mesmo dessa solidão, por causa dela mesmo, foi possível a Sainte-Colombe criar uma sétima corda para a viola e assim, com o instrumento, ele teria todas as possibilidades da voz humana, da criança, da mulher, do homem, essa última, "brisée" e tornada grave quando a criança se torna um homem. E assim se encontram o adolescente que perdeu a voz, o discípulo, e o homem taciturno, seu mestre.

Uma das questões que o livro oferece a seu leitor é sem dúvida esta: o que é a música, afinal? O mestre reconhece a destreza de seu discípulo com os instrumentos musicais, mas, diz ele; "você nunca será um músico", pois ser músico e tocar música são coisas diferentes e a música não é feita para agradar ao rei ou ao mundo, grita ele. O livro é também a história do mestre e seu discípulo que teve, este último, que descobrir a perda e as lágrimas para ser um músico e isso o mestre não pôde ensinar, mas pôde dar. E Sainte-Colombe deu-lhe as lágrimas junto com sua obra, "Le Tombeau des regrets", o túmulo das lamúrias.

${ }^{5}$ QuignARD. La haine de la musique. 
O livro e o filme são uma reflexão sobre a impossibilidade de ensinar e possibilidade de transmitir algo que escapa às palavras e a qualquer gramática que sustente os métodos.

Fez parte do ensino de Sainte-Colombe levar o discípulo para ouvir o som do pincel de seu pintor favorito, no momento mesmo de seu trabalho ou a voz de atrizes que exercitavam a ênfase de sua expressão ou, finalmente, o ruído que fazia a urina quente de um jovem derretendo a neve. A propósito desse ensinamento, em que se observam coisas aparentemente insignificantes e inacabadas, o mestre ressalta a seu discípulo: "vós acabais de aprender sobre aquilo que se destaca ou que cai dos ornamentos". (TLMM, p.63)

O que o romance silencia, pela impossibilidade mesmo de a palavra fazer música, ser só música, o cinema exibe, fazendo ouvir a música, a beleza extraordinária da música dramática, radical, contundente de Sainte-Colombe. Se no romance a música ecoa no silêncio mesmo da letra impressa, no cinema, ela se ouve em espetáculo.

Impossível tecer comentários de valor entre os dois códigos, o literário e o cinematográfico, mas na tela, Pascal Quignard, que trabalhou na adaptação cinematográfica de seu livro, constrói um espaço de cor, brilho e sombra, semelhante ao que se pode admirar na pintura de Georges de La Tour, sobre o qual Quignard escreve La nuit et le silence. ${ }^{6}$ Nesse livro, ele afirma: "houve duas grandes candeias na nossa história e elas se encontram no tempo: as lições das trevas da música barroca, as telas de Georges de La Tour." (LNLS, p.9)

Numa parte extraordinária do filme, em que se representa o ofício das trevas, pode-se notar a presença da pintura de Georges de La Tour, como um cenário vivo, com a cor vermelha de suas velas acesas, sopradas por uma criança cantora do coro. Aí se enlaçam, cromática e musicalmente, temas que se desenvolvem discursiva e repetidamente na obra de Quignard: as luzes, as sombras, a música, o silêncio.

A esse respeito ele afirma em livro sobre a pintura de Georges de La Tour:

Houve duas grandes candeias em nossa história e elas coincidiram no tempo: as lições das trevas da música barroca, as candeias das telas de Georges de La Tour. Os ofícios das Trevas da semana santa constituíam um rito no qual apagavam-se uma a uma, durante o canto, as letras hebraicas que formam o nome de Deus e, uma a uma, graça ao sopro de uma criança vestida de vermelho, as velas que as representavam na obscuridade da agonia.(LNLS, p.9)

Como leitores do livro e espectadores do filme, podemos notar que há uma singular relação entre a página branca e a tela brilhante de luz, pois entre as duas, num espaço virtual, intervalar, o silêncio, a imagem e a música tornam-se paradoxalmente possíveis, num mesmo tempo, numa outra lógica num outro compasso. Tal efeito só se revela possível através de uma dissimetria poética, da qual só podemos falar a partir de uma retórica especulativa, da qual fala Pascal Quignard em seus ensaios e que, parece-me, sustenta toda sua obra.

A última cena do livro é o reencontro do mestre e seu discípulo já famoso, que o procura para confessar que procura a dor e as lágrimas, implorando-lhe: "Senhor,

\footnotetext{
${ }^{6}$ Quignard. La nuit et le silence - Georges de La Tour. (As citações desse livro serão precedidas pelas iniciais LNLS, seguidas do número da página.)
} 
posso pedir-lhe uma última lição?", ao que lhe responde o Senhor de Sainte-Colombe, com uma voz surda: "Senhor, posso tentar uma primeira lição?", continuando: "A música apenas faz falar o que a palavra não pode falar. Assim, ela não é totalmente humana. O senhor enfim descobriu que ela não é para o rei?".

Respondendo-lhe, Marais afirma que a música teria seu sentido em Deus, ao que o mestre retruca: "Vós vos enganais, pois Deus fala". Segue-se todo um jogo de perguntas e tentativas de respostas relativas ao sentido da música, para finalmente o Senhor de Sainte-Colombe concluir que a música se faz pela sombra das crianças, pelos estados que precedem a infância, quando não havia nem o sopro, nem a luz.

E assim Sainte-Colombe passa a seu discípulo sua obra inédita, as árias do "Túmulo das lamentações" e mais ainda a viola de sua filha amada, nesse momento em que o antigo discípulo já teria feito, em sua solidão e sua dor, a aprendizagem das lágrimas, pois a música fala justamente aí onde as palavras fracassam. Entretanto, mais do que passar pela corda tensa da dor, Marais tenha podido ultrapassar o círculo estreito da melancolia.

A

\section{RÉ S U M É}

ce texte est une réflexion sur le livre Tous les matins $d u$ monde et le film de même titre qui ont comme sujet la relation du musicien Monsieur de Sainte Colombe et son disciple Marin Marais. Cette relation pose la question de ce qu' est la musique et la possibilité de son enseignement.

\section{MOTS - CLÉS}

roman, film, musicalité, images visuelles

\section{REFERÊNCIAS BIBLIOGRÁFICAS}

Lapeyre-Desmaison, Chantal. Pascal Quignard le solitaire. Paris: Les Flohic, 2001.

Quignard, Pascal. La haine de la musique. Paris: Gallimard, Folio, 1996.

Quignard, Pascal. La nuit et le silence - Georges de La Tour. Paris: Flohic, 1995.

Quignard, Pascal. Tous les matins du monde. Paris: Gallimard, Folio, 1991. 